\title{
Correction to: Intracerebral Hemorrhage-Induced Brain Injury in Rats: the Role of Extracellular Peroxiredoxin 2
}

\author{
Liheng Bian ${ }^{1,2} \cdot$ Jingwei Zhang ${ }^{1} \cdot$ Ming Wang ${ }^{1} \cdot$ Richard F. Keep ${ }^{1} \cdot$ Guohua Xi ${ }^{1} \cdot$ Ya Hua $^{1}$ \\ Published online: 9 August 2019 \\ (C) Springer Science+Business Media, LLC, part of Springer Nature 2019
}

Correction to: Transl. Stroke Res.

https://doi.org/10.1007/s12975-019-00714-x

In Fig. 1, molecular weight of peroxiredoxin 2 (PRX-2) is $22 \mathrm{kDa}$ rather than $32 \mathrm{kDa}$.

The online version of the original article can be found at https://doi.org/ 10.1007/s12975-019-00714-x

$\triangle$ Ya Hua

yahua@umich.edu

1 Department of Neurosurgery, University of Michigan, R5018 BSRB, 109 Zina Pitcher Place, Ann Arbor, MI 48109-2200, USA

2 Department of Neurology, Beijing Tiantan Hospital, Capital Medical University, Beijing, China 

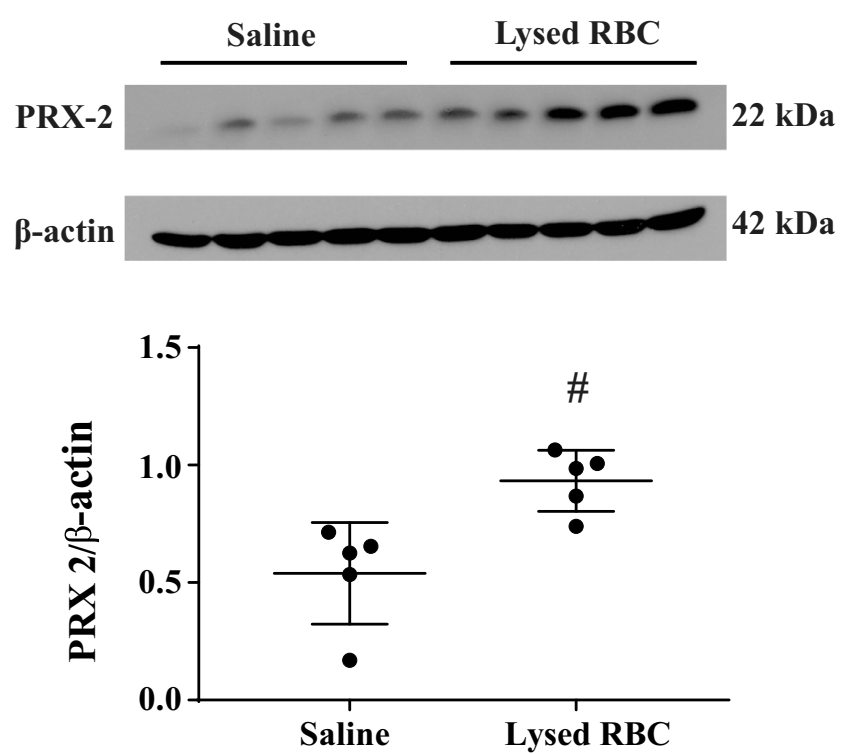

Fig. 1 Western blot assessing PRX-2 levels in the ipsilateral basal ganglia at $1 \mathrm{~h}$ after lysed RBCs or saline injection $(15 \mu \mathrm{l})$. Values are means $\pm \mathrm{SD}$; $n=5$ for both groups; $\# P<0.01$ vs. saline group by the Student $t$ test

The authors regret the errors.

Publisher's Note Springer Nature remains neutral with regard to jurisdictional claims in published maps and institutional affiliations. 